\title{
INTERthesis
}

\section{BIOPOLÍTICA E BRUTALISMO EM CHAVE ESTRATÉGICA}

Biopolitics and Brutalism in a Strategic Perspective

Peter Pál Pelbart

Doutor em Filosofia pela Universidade de São Paulo.

Professor titular da Pontifícia Universidade Católica de São Paulo, São Paulo, Brasil. https://orcid.org/0000-0003-1880-0113 (C)

A lista completa com informações dos autores está no final do artigo

\section{RESUMO}

Como repensar a biopolítica no contexto do neoliberalismo? A que ponto a trilha aberta por Foucault mantém sua validade? Como a perspectiva de Maurizio Lazzarato, com seu conceito de "máquina de guerra do capital", e o de Achille Mbembe, com o de "brutalismo", se prestam a repensar a relação entre corpo, guerra e capital?

PALAVRAS-CHAVE: Biopolítica. Lazzarato. Mbembe. Máquina de guerra do capital. Brutalismo. Corpo.

\section{ABSTRACT}

How to rethink biopolitics in the context of neoliberalism? To what extent does the trail opened by Foucault retain its validity? How does Maurizio Lazzarato's perspective, with his concept of "Capital's war machine" and Achille Mbembe's "Brutalism", allow to rethink the relationship between body, war and Capital?

KEYWORDS: Biopolitics. Lazzarato. Mbembe. Capital's war machine. Brutalism. Body.

\section{INTRODUÇÃO}

O título deste texto faz alusão ao subtítulo de um livro recente de Maurizio Lazzarato, intitulado Fascismo ou revolução: Neoliberalismo em chave estratégica (LAZZARATO, 2019). Com sua habitual irreverência teórica, o autor coloca em questão a validade da noção de biopolítica para o contexto contemporâneo e salienta seu eurocentrismo. "Em Foucault, falta metade da "narrativa" genealógica sobre os "poderes", os "sujeitos" políticos e as instituições, já que ele limita sua análise à Europa” (LAZZARATO, 2019, p. 86). Já Hanna Arendt, em seu Origens do totalitarismo, postulava que na Segunda Guerra Mundial métodos anteriormente reservados apenas aos ditos "selvagens" passaram a ser aplicados também aos povos ditos "civilizados" da Europa. Ou seja, o que antes era perfeitamente aceitável em relação aos negros foi aplicado também aos brancos em solo europeu, daí o escândalo da Shoá junto às democracias (ARENDT, 1989).

Perguntamos se é tão importante saber onde começa o pior. Como diz Mbembe: 
No fim, pouco importa que as tecnologias que culminaram no nazismo tenham sua origem na plantation ou na colônia, ou, pelo contrário - a tese foucaultiana -, que nazismo e stalinismo não tenham feito mais do que ampliar uma série de mecanismos que já existiam nas formações sociais e políticas da Europa ocidental (subjugação do corpo, regulamentações médicas, darwinismo social, eugenia, teorias legais sobre hereditariedade, degeneração e raça). Um traço persiste evidente: no pensamento filosófico moderno, assim como na prática e no imaginário político europeu, a colônia representa o lugar em que a soberania consiste fundamentalmente no exercício de um poder à margem da lei (ab legibus solutus) e no qual a "paz" tende a assumir o rosto de uma "guerra sem fim" (MBEMBE, 2018, p. 30).

Se como o afirma Mbembe, é preciso buscar a gênese do biopoder na colonização, na plantation, não caberia reformular o postulado de Agamben? Se o paradigma biopolítico do Ocidente deita raiz na escravidão e na plantation, ainda que desemboque no campo de concentração, não seria preciso recuar no tempo para afinar tal teorização?

Para Lazzarato, a própria polaridade foucaultiana entre o poder de morte atrelado à soberania (fazer morrer, deixar viver) e a gestão da vida (fazer viver, deixar viver), é falsa ou limitada. Pois "do ponto de vista do 'mercado mundial', o poder de morte nunca deixou de se exercer", como o mostra o século XX e a nossa atualidade (LAZZARATO, 2019, p. 87). Mas o autor não se limita a criticar a extensão abusiva da noção de biopolítica, tanto no tempo como no espaço, já que ousa contestar a pertinência do próprio conceito, chamando a atenção para a impertinência do radical bio na etimologia da palavra, ao frisar que nem o racismo nem a biopolítica têm qualquer fundamento biológico, sendo este apenas um recorte contingente. Com o que pode concluir que o biopoder não é a forma geral do poder contemporâneo, já que ele foi reconfigurado pela máquina de guerra do capital (LAZZARATO, 2019). É onde sua hipótese aparece com toda clareza:

A vida de que se trata na biopolítica contemporânea é a vida, política, do capital. Opondo a "economia política do poder" à "crítica da economia política marxiana", Foucault obscurece a compreensão das transformações do exercício do poder que se produziram a partir da primeira metade do século $\mathrm{XX}$, momento em que as duas economias se interpenetraram profundamente sob a hegemonia do capital. A primazia da "economia política do poder" sobre a "crítica da economia política" é um evidente erro de interpretação do capitalismo do pós-68 que encontramos reproduzido fielmente pela teoria crítica, sobretudo nas correntes do movimento feminista. O debate entre Nancy Fraser e Judith Butler, cujos termos foram desajeitadamente expressos pela oposição entre "politica social" (economia política) e "política de identidade" (economia política do poder), remete a essa funesta oposição (LAZZARATO, 2019, p. 89). 
Já podemos salientar o ponto de apoio do autor, presente ainda no livro anterior escrito com Éric Alliez, intitulado Guerres et Capital (ALLIEZ; LAZZARATO, 2016): a centralidade da "máquina de guerra do capital", onde a indissociabilidade entre guerra e capital tem por objetivo maior produzir fraturas na população, e assim, em última instância, evitar o risco de uma revolução. Portanto, "a "vida" que está em jogo aqui, segundo ele, não é a vida biológica da população, mas a vida política da máquina capitalista e das elites que constituem sua subjetivação. A salvaguarda destas implica necessariamente colocar em perigo a vida das populações (LAZZARATO, 2019).

É o que a pandemia do COVID-19 demonstra abundantemente. Até o último minuto, as elites de cada país trataram de adiar as medidas que pusessem em risco a normalidade econômica, e só decidiram "cuidar da vida" quando os gravemente afetados não mais dispunham de aparelhos para respirar, desbordando os hospitais, e os cadáveres já mal cabiam nos crematórios ou cemitérios. Como o diz Lazzarato, antes mesmo da pandemia:

Por essa "vida" e por sua reprodução o capital está disposto a sacrificar, sem qualquer escrúpulo, a saúde, a formação, a reprodução e a moradia de várias camadas da população, ou seja, sacrificar a vida dos proletários, como sempre fez, como continua e sempre continuará a fazer, reconduzindo-a, relação de força permanente, ao mínimo (os serviços mínimos dos neoliberais significam exatamente isso) (LAZZARATO, 2019, p. 92).

A demora dos governos da Itália, Espanha, Estados Unidos, Grã-Bretanha, Irã, para nem mencionar o caso brasileiro, em tomarem as medidas necessárias diz muito da transformação da saúde em mercadoria e do descaso em que se encontra a "vida" da população.

O que teria impedido Foucault de enxergar isso no seu tempo? Foi, segundo Lazzarato, a obsessão do filósofo, nos anos 70, de se debruçar sobre o "excesso de poder", tal como exercido na prisão, no hospital, na escola - toda essa microfísica inteiramente deixada de lado pelo marxismo da época. Não nos cabe, aqui, julgar tal avaliação de Lazzarato. Basta dizer que Foucault jamais pretendeu construir uma teoria geral do poder, muito menos sustentar qualquer hipótese que valesse também para o futuro. Se os tempos são outros, seria preciso examinar o que daquelas teorizações ainda valem, quais outras se impõem, o quanto mecanismos diversos se sobrepõem e se intercambiam. Em todo caso, é preciso notar que quando cunha o conceito de biopoder ou biopolítica, imediatamente postula sua vizinhança com o que chama de tanatopolítica, cujo apogeu foi a Shoá. Se as guerras não se fazem mais em nome do soberano, mas da população, tal deslocamento não impede que elas sejam conduzidas com sacrifícios crescentes. "Os 
massacres se tornaram vitais. Foi como gestores da vida e da sobrevivência dos corpos e da raça que tantos regimes puderam travar tantas guerras, causando a morte de tantos homens" (Foucault, 2013, p. 147). Disso o autor conclui que o genocídio moderno não é uma continuação do antigo direito de matar, porém se deve ao fato de que o poder agora se exerce ao nível da vida e da espécie (FOUCAULT, 1976). É onde Lazzarato enxerga uma lacuna - da subjugação ao capital. Mas Foucault jamais ignorou a relação entre o biopoder e o capitalismo, ressaltando a importância da inserção dos corpos na produção, do ajuste entre os fenômenos globais da população e os processos econômicos. "O investimento sobre o corpo vivo, sua valorização e a gestão distributiva de suas forças foram indispensáveis naquele momento" (FOUCAULT, 2013, p. 152).

Simplesmente, não foi este o foco central da análise de Foucault. A grande novidade estaria mais na emergência da "vida" na história, na "bio-história": "a entrada dos fenômenos próprios à vida da espécie humana na ordem do saber e do poder -, no campo das técnicas políticas". Afinal, por biopolítica Foucault entende "o que faz com que a vida e seus mecanismos entrem no domínio dos cálculos explícitos, e faz do poder-saber um agente de transformação da vida humana" (Foucault, 2013, p. 154), de modo que a própria espécie passa a estar em jogo. Para nossos propósitos, aqui, basta evocar essas poucas considerações para mostrar que Foucault não "ignorou" tais elementos. Apenas, como Lazzarato mesmo o reconhece, no momento em que escrevia, nos anos 70, o capital e sua dimensão bélica não tinham ainda deposto de tal forma o poder do Estado. Se a biorregulação das populações na época remetia ao Estado, a centralidade ou a função de coordenação que o próprio Estado ainda exercia foram desde então drasticamente diminuídas, desembocando no que hoje assistimos: o Estado tornou-se função do capital e de suas "guerras". E suas "guerras" visam antes de tudo dividir a população, fraturá-la segundo diversas linhas de segregação e, no limite, expô-la à morte, muito mais do que otimizar sua saúde (fazer morrer, mais do que fazer viver).

Argumentar que a racionalidade do capital recomendaria preservar as condições de sua acumulação, isto é, defender a vida, a natureza ou o planeta, diz o autor, é "não compreender nada de sua "racionalidade", e como o notou Deleuze, 'o dinheiro, o capitaldinheiro, é um grau de demência tal que só encontraria um equivalente em psiquiatria: 0 chamado estado terminal" "Tudo é racional no capitalismo, exceto o capital ou o capitalismo" (DELEUZE, 2006, p. 332). No fundo, trata-se da natureza predatória, destrutiva e mortífera do próprio capitalismo. Daí o chamamento de Lazzarato de retomar o pensamento estratégico abandonado em algum momento por Foucault. 
De fato, até 1975 o filósofo da genealogia do poder invertia a fórmula de Clausewitz, postulando que a política é a continuação da guerra por outros meios. Assim, a guerra civil aparecia como a base das relações de poder. Mais tarde, essa hipótese que ele mesmo chamara de "nietzschiana" foi abandonada, em favor da teorização sobre a governamentalidade (ALLIEZ; LAZZARATO, 2016; PELBART, 2019). Lazzarato mostra a necessidade de um resgate da "hipótese nietzschiana", insistindo na dimensão da guerra hoje, e da guerra civil, que subjaz às relações de poder atuais, guerra contra a própria população, guerra de subjetividades, guerra contra as minorias - em suma, fascismo. É onde tocamos nossa mais crua atualidade: a aliança "natural" entre neoliberalismo e fascismo, que se desenha em vários países como se fosse uma novidade, e não o que certo pensamento dos anos 60 negligenciou: "política e guerra são estratégias 'sempre prestes a se interpenetrar' sob a hegemonia da máquina do Capital." Por conseguinte, se "as duas estratégias estão à disposição do poder (da máquina do capital), elas também podem ser mobilizadas para a revolução" (LAZZARATO, 2020, p. 97). Em outros termos, não deveríamos deixar a conflitualidade resolver-se em governamentalidade, sob pena de ver fecharem-se as brechas que poderiam desembocar numa reversibilidade revolucionária. Como o diz Benjamin, todo fascismo é uma revolução abortada.

Obviamente, o passo dado por Lazzarato em sua discussão com Foucault se deve à impotência do pensamento 68 diante das novas estratégias do neoliberalismo, como ele confessa:

Não se trata de renegar uma das conquistas do pensamento 68 , a articulação da micropolítica e da macropolítica, mas de conceber seu agenciamento. Porém, a macropolítica, pela qual deve passar a microfísica sob pena de desaparecer (Deleuze e Guattari), é a da revolução. Os movimentos saídos de 68 não souberam prever as artimanhas do capital, e ficaram desarmados perante suas "excrescências" fascistas (LAZZARATO, 2019, p. 100).

\section{RECRIAR O VIVÍVEL A PARTIR DO INVIVÍVEL}

Talvez a melhor descrição da "excrescência" fascista proveniente dessa dimensão bélica do capital tal como descrita por Lazzarato, apesar da distância entre ambos, tanto teórica como temática, esteja no recente livro de Achille Mbembe, Brutalisme (MBEMBE, 2020). Ali ele trata de analisar as novas técnicas biopolíticas (ou necropolíticas) que se exercem diretamente sobre os corpos: fraturação, fissurização, esgotamento. O poder aparece como uma força geomórfica cujo objetivo é submeter o vivente a um processo de 
extração comparável ao que se usa no caso do gás de xisto. "Visto sob este ângulo, a função dos poderes contemporâneos é, mais do que nunca, tornar possível a extração”. (MBEMBE, 2020). A diferença é que o material exposto à extração é o corpo humano, cuja capacidade de resistência cabe reprimir ou desmantelar, submetendo-o a todo tipo de procedimentos ou situações que provocam intoxicações, anomalias congênitas, perturbações neurológicas, hormonais. Ou seja, há uma espécie de "destruição criadora", geológica, molecular, neurológica. Talvez, desde Nietzsche e Foucault, jamais o poder tenha sido analisado de maneira tão radicalmente "materialista", isto é, na sua incidência direta e molecular sobre os corpos, com seus efeitos deletérios, corporais e subjetivos. Contudo, é a partir do continente africano que esse processo, ou essa matriz de um poder obcecado em demolir e reconfigurar, foram concebidos por Mbembe. Por isso, foi incluído num arco que o autor batizou de devir-negro do mundo, na medida em que se trata de um processo global que pretende dispor dos corpos de largas parcelas da população tal como na colonização o escravagismo tomou de assalto o corpo negro proveniente da África (MBEMBE, 2020). O autor confessa ter compreendido que o continente africano "não passava, na verdade, de um laboratório de mutações de ordem planetária. Desde então, foi a essa virada planetária do predicado africano e a seu parelho, o devir-africano do mundo, que, junto a outros, me atrelei" (MBEMBE, 2020, p. 13).

No que consiste, mais precisamente, tal reconfiguração da espécie humana almejada e efetuada, entre outras, pelas mudanças na bioesfera e na tecnoesfera? Se não "abolir a sociedade, ao menos esculpi-la e, eventualmente, substituí-la por um nanomundo, o dos dispositivos celulares, neuronais e computacionais" (MBEMBE, 2020, p. 15). Em última análise, o projeto do brutalismo consiste em transformar os humanos em matéria e energia disponíveis para a extração, tal como sucedeu com a terra.

O sentimento do fim de mundo, tanto do ponto de vista do tempo (abolição da "futuração") quanto do espaço (esgotamento dos recursos naturais, estreitamento da Terra), não pode ser dissociado do descolamento virtual de uma plutocracia mundial, que deixa à míngua e no pântano social a maior parte da população, impondo-lhe situações extremas. Como se reatualizássemos o que caracterizou um período da colonização, "recriar o vivente a partir do invivível". O invivível atual, porém, tem novas características, tóxicas, neuronais, moleculares, dado o estado de "combustão do mundo" a que teríamos chegado.

Quer se trate dos afetos, das emoções, dos sentimentos, da linguagem, do desejo, do sonho ou do pensamento, em suma, da vida, diz Mbembe, nada parece escapar à 
captura do capital. Ele capturou até o fundo do mundo, deixando com frequência atrás de si vastos campos de escombros e toxinas, detritos de homens corroídos de chagas, cancros e furúnculos. Tudo tornado uma fonte potencial de capitalização, o capital se fez mundo, um fato alucinatório de dimensão planetária, produtor, numa escala ampliada, de sujeitos a um só tempo calculadores, ficcionais e delirantes. O capital se fez carne, tudo se tornou uma função do capital, inclusive a interioridade... O capital se tornou nossa infraestrutura comum, nosso sistema nervoso, a mandíbula transcendental que doravante desenha o mapa de nosso mundo e de seus limites psicofísicos (MBEMBE, 2020, p. 66). A algoritmização generalizada não passa da concretização desse processo de financeirização de cada nervo, célula, tecido, neurônio, sensação, pensamento, que o autor chamará de "tecnolatria".

A "fronteirização" é o elemento que traça incessantemente novas fronteiras, triagens, interdições, reclusões, enclaves, campos, expulsões, e com frequência é dirigida contra populações cujo meio foi previamente destruído e para quem, com razão, em algum momento só resta a fuga - é como se transformam estrangeiros em enjeitados por toda parte. É, como o mostrava Lazzarato, a guerra contra a população, ou como o diz Mbembe, contra certos corpos de abjeção, ou caças, como o diz Grégoire Chamayou (CHAMAYOU, 2020). Guerras químicas ou bacteriológicas, monitoradas por satélites ou acionadas por drones à distância de um oceano, que produzem em massa má formação infantil, paralisias, doenças pulmonares, restos de uranio nos cabelos, milhares de casos de câncer, deformações congênitas - fissurização. Não podemos deixar de ver nessa descrição uma prefiguração do ambiente em que surge uma doença cuja característica principal consiste na dificuldade de respirar.

Mas outros componentes entram na análise dos mecanismos de poder atuais. Já no Crítica da razão negra Mbeme alertava para o fato de que o que se fez com os negros no passado se expandia atualmente para camadas cada vez mais amplas da população. $O$ escravagismo e o colonialismo terão revelado também a dimensão patriarcal, fálica, orgástica, da ordem da tumescência, da penetração, de um regime de gozo virtualmente infinito dos corpos racializados pela dominação genital do colonizador. É o que o historiador chama de "virilismo", através do qual o homem branco, tão reprimido em seu continente de origem, libera sem culpa e descarrega sobre o corpo racializado do nativo toda sua volúpia antes contida. A colônia terá sido o laboratório para uma experimentação concreta da relação entre poder e sexo, e da inscrição do poder dominador sobre o corpo racializado, erotizado e subjugado do dominado. As pulsões sexuais e sádicas terão encontrado aí um 
terreno de liberação irrefreada, que prenunciavam, talvez, o que o neoliberalismo retomou à sua maneira. A colônia como um buraco, onde se despeja e se experimenta toda a agressividade, o fantasma da posse e possessão absolutas. Nesse buraco, assiste-se à produção de um corpo aviltável ao infinito à mercê do gozo do colono obcecado pelo ato sexual, investindo, portanto, num corpo que deve dar conta das fantasias as mais perversas. Resta o falo que para ser, tem necessidade do Outro apenas como suporte para sua própria manifestação, em busca de seu momento epifânico em que expressa e afirma seu poder infinito. Diante de tal masculinismo e racismo, a mulher aparece como mera imagem, abertura e cloaca, matéria para a combinatória genital. A falocracia é um componente do brutalismo, mas também é fruto de uma projeção, a do falo todo poderoso do negro, ameaça de estupro da branca. De um lado a outro, a falocracia como um jogo especular, ou melhor, projetivo, em que se constitui como encobridor de uma impotência, ou como medo da potência alheia. Embora se possa objetar que a colonização da África e do Brasil foram muitíssimo diferentes, podemos dizer que reconhecemos, também entre nós, em nosso contexto machista e sexista, vários traços elencados por Mbembe. É até um dos componentes mais dominantes em nosso neofascismo tropical. O superinvestimento do falo, nesse sentido, é a contraface de um esgotamento da própria masculinidade e virilidade. É a zona frenética do poder, diz Mbembe. Cada violência do Estado, desde o bombardeio de populações até a repressão policial, mas também cada fanfarronice de um Bolsonaro e as bananas cotidianamente enviadas aos repórteres, são vividos com uma volúpia viril. No fundo, tudo isso atesta que o falo está sendo destituído cotidianamente por todo tipo de deslocamentos, como Preciado o tem tematizado, Silvia Frederici o completa, o próprio Lazzarato o reconhece, Mbembe o amplia, e as lutas feministas o demonstram cotidianamente (PRECIADO, 2018; FREDERICI, 2017; LAZZARATO, 2020; MBEMBE, 2020).

Mas algo mais se acresce, nessa mutação subjetiva.

A época, manifestamente, busca se liberar do inconsciente. Suas margens erógenas, os circuitos pulsionais e a matéria significante apontam para uma era que não quer saber nada da perda, da dívida, nem mesmo da autoridade. Gozar é acumular, certo, mas sobretudo dispender, evacuar e dilapidar. Mas é também uma época caracterizada pela recusa da última palavra. A esfera pública remete a esse lugar impossível, receptáculo de autorretratos impossíveis. Uma nova psicologia das massas se desenha, pois, e com ela uma nova forma política, a dos afetos (MBEMBE, 2020, p. 87).

Então o que significa, dado o contexto tecnólatra e algorítmico, patriarcal e falocêntrico, governar? « Governar é, em cumplicidade com o capital, produzir estruturas 
do desejo e dos modos de gozar" (MBEMBE, 2020), responde Mbembe. Mas governar é também instaurar novas categorias na divisão do mundo (excedentários racializados, errantes, insolventes, infectados, vulneráveis), e, portanto, desenhar novas fronteiras e mecanismos de triagem e seleção, de elitização e desqualificação. E sobretudo, como o sugeriu Foucault ao ressaltar a moldagem política da espécie humana, e as contribuições de Mbembe, trata-se de fraturar, fissurizar, esgotar e desmantelar o corpo humano a fim de disponibilizá-lo, como matéria e energia, para uma reformatação da espécie, num experimento que o moldaria e o submeteria aos mecanismos capitalísticos e bélicos de punção e extorsão da vida cujos limites mal vislumbramos.

Caberia encerrar essa trajetória ziguezagueante num tom menos apocalíptico, apesar da desolação, do pânico e da paralisia que tomou conta do planeta neste momento de pandemia em que este texto está sendo finalizado. Cedo demais para tecer qualquer consideração a respeito desse momento e seus efeitos futuros, muito menos para dele extrair qualquer conclusão que diga respeito ao que foi evocado acima. Não faltarão análises as mais diversas, foucaultianas, agambenianas, zizekianas, tiqqunianas, harawayanas, para ficarmos apenas num dos espectros do pensamento político. Mbembe e Lazzarato, aqui evocados, não deixarão eles tampouco de manifestar suas conjecturas, assim como Déborah Danowski e Eduardo Viveiros de Castro, no rastro do livro escrito conjuntamente: Há mundo por vir? Em todo caso, nunca como antes se expôs com tamanha evidência a que ponto a vida e o corpo estão no centro do furacão, ali onde biopolítica, guerra e capitalismo se entrelaçam de modo indissociável.

\section{REFERÊNCIAS}

ALLIEZ, Éric, LAZZARATO, Maurizio. Guerres et Capital. Paris: Amsterdam, 2016.

CHAMAYOU, Grégoire. Teoria do drone. São Paulo: Ubu, 2016.

DELEUZE, Gilles. Sobre o capitalismo e o desejo. In DELEUZE, Gilles. A ilha deserta David Lapoujade (org.), trad. Luiz B. L. Orlandi. São Paulo: lluminuras, 2006, p. 332.

FEDERICI, Silvia. A bruxa e o Calibã. São Paulo: Ed Elefante, 2017.

FOUCAULT, Michel. História da sexualidade I: A vontade de saber. Paris: Gallimard, 1975.

LAZZARATO, Maurizio. Fascismo ou revolução: o neoliberalismo em chave estratégica. São Paulo: n-1 edições, 2019. 
MBEMBE, Achille. Brutalisme. Paris: La Découverte, 2020 (no prelo em português pela $\mathrm{n}$-1 edições).

MBEMBE, Achille. Crítica da razão negra. São Paulo: n-1edições, 2019.

MBEMBE, Achille. Necropolítica. São Paulo: n-1edições, 2018.

PELBART, Peter Pál. Ensaios do assombro. São Paulo: n-1 edições, 2019.

PRECIADO, Paul B. Testo Junkie. São Paulo: n-1 edições, 2018.

\title{
NOTAS
}

\author{
Peter Pál Pelbart \\ Doutor em Filosofia pela Universidade de São Paulo. \\ Professor titular da Pontifícia Universidade Católica de São Paulo, São Paulo, SP, Brasil. \\ (1) https://orcid.org/0000-0003-1880-0113
}

\section{AGRADECIMENTOS}

Não se aplica

\section{CONTRIBUIÇÃO DE AUTORIA}

Não se aplica

Concepção e elaboração do manuscrito: Peter Pál Pelbart

\section{CONJUNTO DE DADOS DE PESQUISA}

Todo o conjunto de dados que dá suporte aos resultados deste estudo foi publicado no próprio artigo.

\section{FINANCIAMENTO}

Não se aplica.

CONSENTIMENTO DE USO DE IMAGEM

Não se aplica

\section{APROVAÇÃO DE COMITÊ DE ÉTICA EM PESQUISA \\ Não se aplica.}

\section{CONFLITO DE INTERESSES}

Não se aplica.

\section{LICENÇA DE USO}

Os autores cedem à Revista Internacional Interdisciplinar INTERthesis os direitos exclusivos de primeira publicação, com o trabalho simultaneamente licenciado sob a Licença Creative Commons Attribution (CC BY) 4.0 International. Esta licença permite que terceiros remixem, adaptem e criem a partir do trabalho publicado, atribuindo o devido crédito de autoria e publicação inicial neste periódico. Os autores têm autorização para assumir contratos adicionais separadamente, para distribuição não exclusiva da versão do trabalho publicada neste periódico (ex.: publicar em repositório institucional, em site pessoal, publicar uma tradução, ou como capítulo de livro), com reconhecimento de autoria e publicação inicial neste periódico.

\section{PUBLISHER}

Universidade Federal de Santa Catarina. Programa de Pós-graduação Interdisciplinar em Ciências Humanas. Publicação no Portal de Periódicos UFSC. As ideias expressadas neste artigo são de responsabilidade de seus autores, não representando, necessariamente, a opinião dos editores ou da universidade.

\section{EDITORES}

Javier Ignacio Vernal e Silmara Cimbalista.

HISTÓRICO - uso exclusivo da revista

Recebido em: 31.03.2020 - Aprovado em: 07-10-2020 - Publicado em: 16.11.2020 